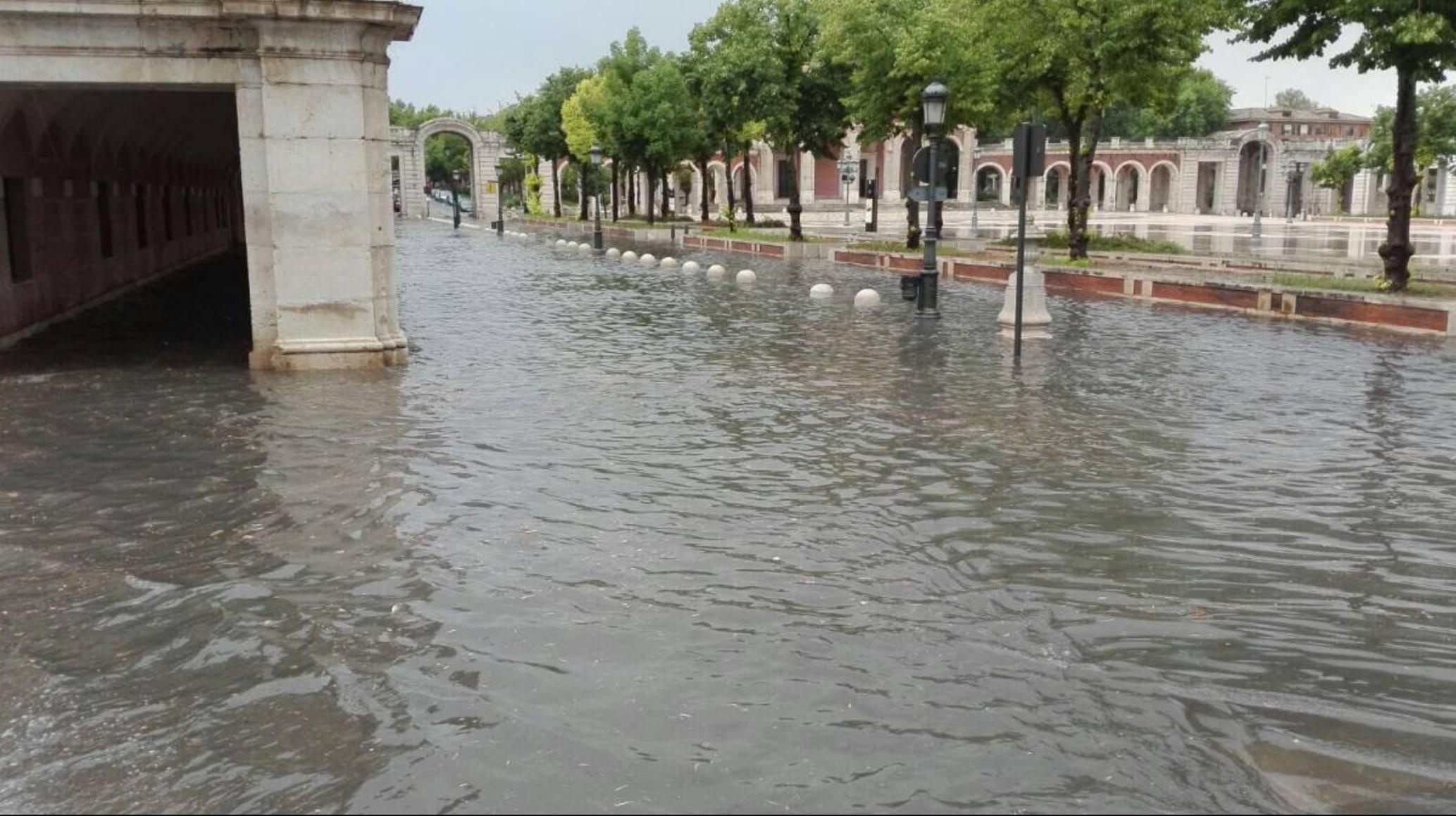

\title{
DANA de principio de verano (Jul-2017)
}

\section{9}

DOI: $10.31978 / 014-18-009-X .59$

\author{
JAIME REY VIDAURRÁZAGA \\ Centro Nacional de Predicción (CNP), Agencia Estatal de Meteorología (AEMET)
}

\begin{abstract}
DANA es el acrónimo meteorológico cuyo significado es "Depresión Aislada en Niveles Altos". Trata de ser la traducción del término anglosajón de cut-off low (baja aislada) en 500 o $300 \mathrm{hPa}$. En la terminología popular equivaldría a lo que el Meteorólogo D. MANUEL LEDESMA JiMENo llamó "gota fría"(término que, posteriormente, adoptó D. MARIANO MEDINA), término popular y periodístico que ha degenerado a ser sinónimo de lluvias intensas en el periodo otoñal en el área mediterránea. Una DANA es un seno de bajas presiones aislada en niveles altos, preferentemente, del vórtice circumpolar. Lo que muchos no conocen es el origen de esta palabra. Proviene en honor del apellido de un meteorólogo coetáneo y compañero de MANUEL Ledesma y Mariano Medina: D. Francisco García Dana, Meteorólogo del antiguo INM, que falleció en 1984.
\end{abstract}

extracto de https://www.tiempo.com/ram/26947/de-donde-procede-el-nombre-meteorologico-de-dana/ FRANCISCO MARTín LEÓN, Meteorólogo

Entre el 5 y el 9 de julio de 2017, la península ibérica se vio afectada por el paso de una depresión aislada en niveles altos depresión aislada de niveles altos (DANA), con tormentas que se extendieron por buena parte de la península, especialmente sobre el sistema Central y su entorno. Este episodio, totalmente convectivo, tuvo una predecibilidad muy pobre y una variabilidad espacial muy elevada. En este capítulo se pretende realizar un ensayo de predicción de medio plazo para el episodio, centrándonos para ello en los días más adversos.

Palabras clave: sistemas de predicción por conjuntos aplicados a la predicción de corto y medio plazo, predicción probabilista, depresión aislada en niveles altos, DANA de principio de verano julio 2017. 


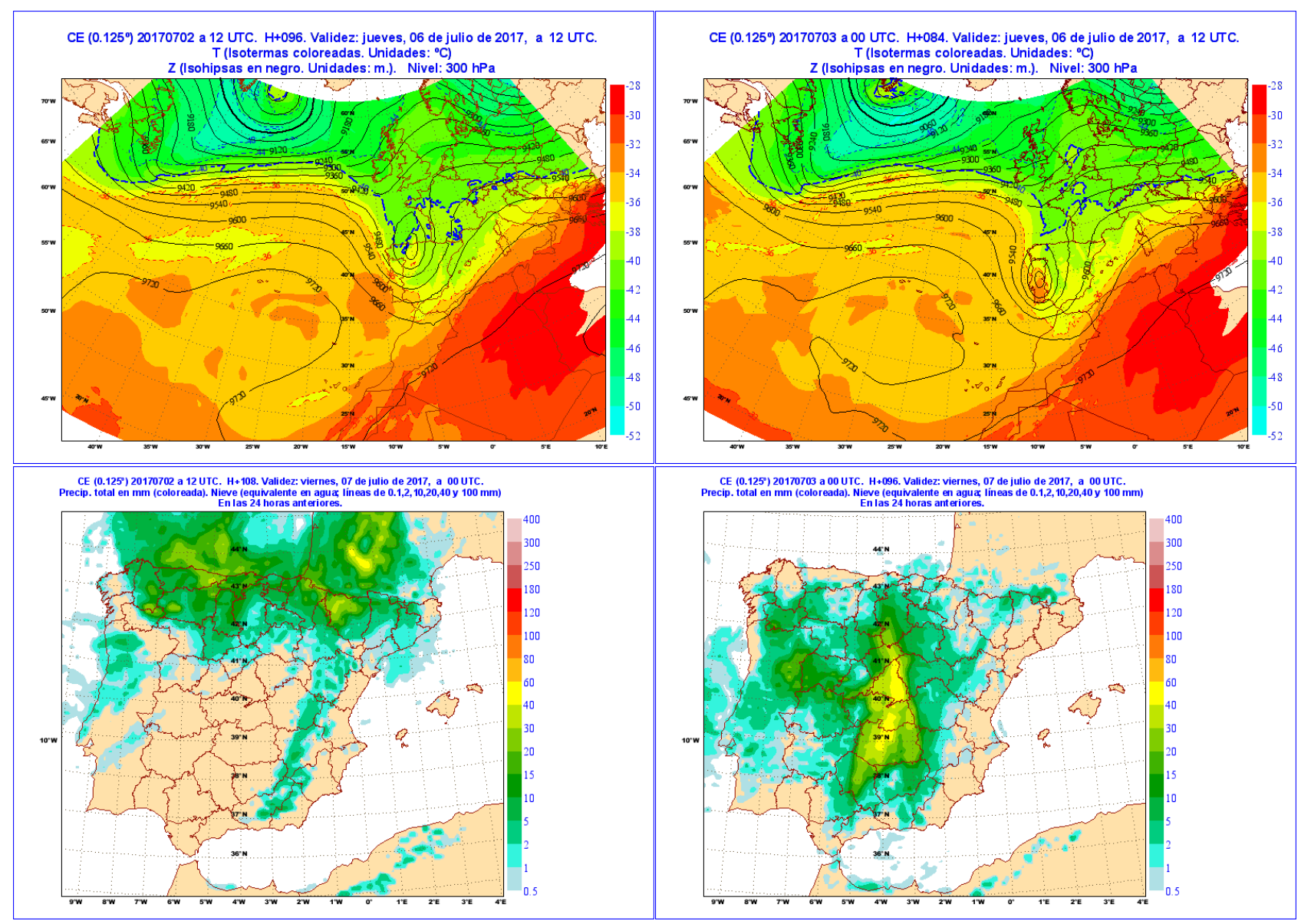

Figura 59.1: Geopotencial en 300 hPa y precipitación acumulada en 24 horas, para las 12 UTC del 06-07-2017, a partir de las pasadas de 12 UTC del 02-07-2017 y de 00 UTC del 03-07-2017 del ECHRES. Agencia Estatal de Meteorología (AEMET).

\subsection{Comportamiento de modelos y SPC}

Las depresiones aisladas en niveles altos, DANA (conocidas por el término cut-off low en inglés), son un fenómeno bastante común en las proximidades de la península ibérica, siendo especialmente frecuentes en los meses de verano [2]. Habitualmente suelen encontrarse con mayor frecuencia en la franja latitudinal entre $35^{\circ} \mathrm{N}$ y $40^{\circ} \mathrm{N}$, aunque en los meses de verano, debido al desplazamiento de la circulación atmosférica hacia al norte, es más habitual encontrarlas en la franja entre $40^{\circ} \mathrm{N} \mathrm{y} 45^{\circ} \mathrm{N}$, justo en el norte de la península ibérica [2]. Así pues, vamos a analizar un tipo de situación típica sobre la Península, pero cuyo comportamiento, debido a su pequeño tamaño y carácter dinámico especialmente caótico, continúa siendo muy complicado de predecir.

\subsubsection{Consistencia entre pasadas de ECHRES}

Una forma de ilustrar esta problemática surge analizando el comportamiento de distintas pasadas del modelo determinista, en nuestro caso el ECHRES (sec. 19.2 en la página 291). Si observamos la Figura 59.1, dos pasadas consecutivas, la del día 2 de julio a las 12 UTC y la del día 3 del mismo mes a las 00 UTC, muestran una evolución muy distinta de la DANA. En la pasada de 12 del día 2, la DANA se desplazaría por el norte peninsular, dejando precipitaciones especialmente intensas en el tercio norte, de entre 30 y $40 \mathrm{~mm}$ el día 6 en Asturias y Huesca, sin afectar prácticamente al suroeste y centro peninsulares. En cambio, la siguiente pasada sitúa la DANA sobre Portugal, con un desplazamiento que llega a ser retrógrado, afectando especialmente al centro peninsular, con precipitaciones entre 40 y $60 \mathrm{~mm}$ en Madrid y el oeste de Castilla-La Mancha. 


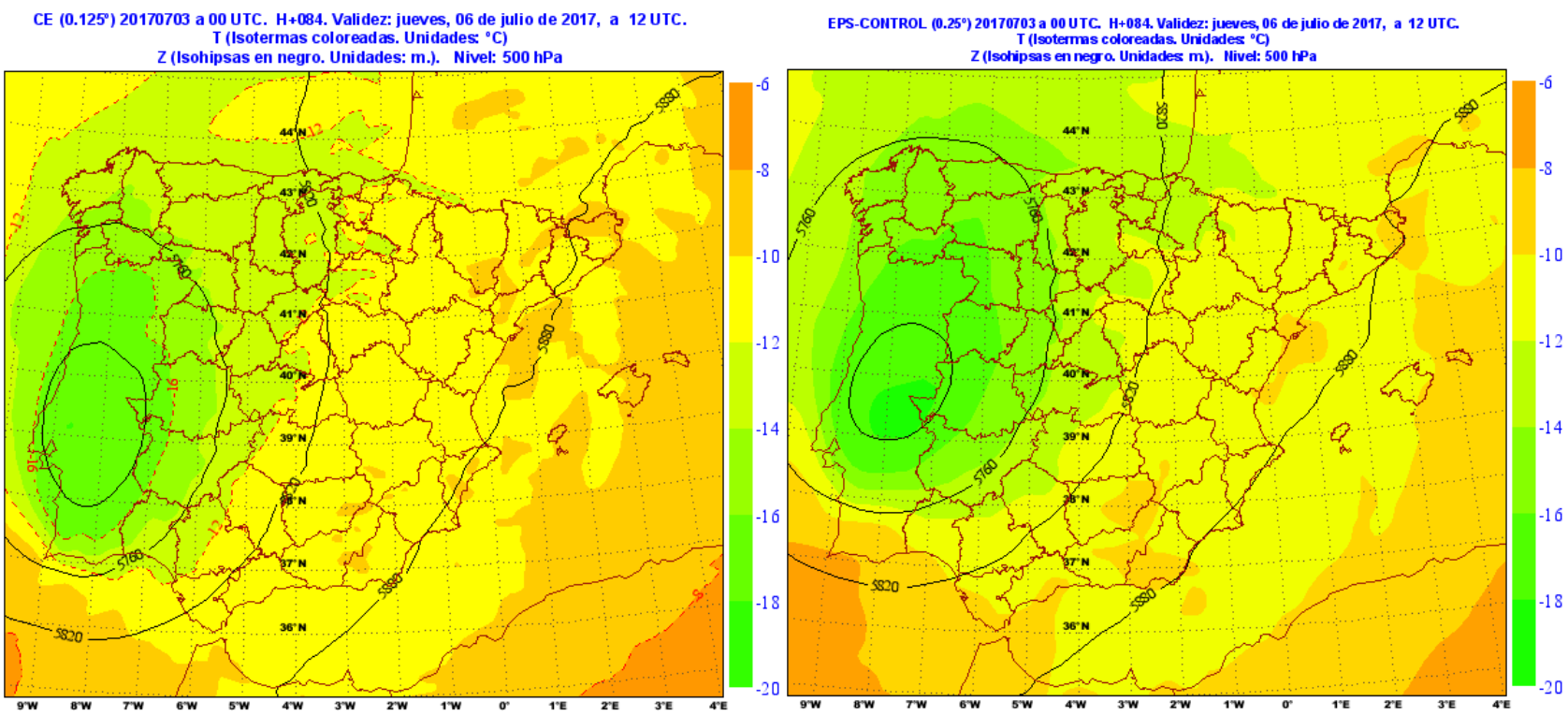

Figura 59.2: Geopotencial en 500 hPa, para las 12 UTC del 06-07-2017, a partir de las pasadas de 12 UTC del 02-07-2017 del ECHRES y del miembro del Control del ECENS. AEMET.

Tal disparidad entre pasadas evidencia la baja predecibilidad (sec. 12 en la página 155) de estas situaciones en el medio plazo, lo que hace que debamos ser especialmente cautos en el uso exclusivo de modelos deterministas, ya que puede llevarnos a grandes errores en la predicción. Por ello, pasamos a analizar el comportamiento del modelo probabilista, en nuestro caso el ECENS (sec. 19.3 en la página 293).

\subsubsection{Control vs determinista}

En un primer estadio es conveniente comparar el miembro de control del ECENS con el ECHRES. Como se puede ver en la Figura 59.2, aunque sinópticamente describen situación parecidas, la posición del núcleo frio se sitúa más al norte en el llamado miembro de control (parte derecha de la figura), lo que puede provocar que varíen significativamente las zonas afectadas por la DANA.

\subsubsection{Dispersión del ECENS}

Lo siguiente que haremos será analizar el geopotencial en $500 \mathrm{hPa}$ del valor medio del ensemble y su desviación estándar normalizada (sec. 27.5.1 en la página 412). Para el día 6 a las 00 UTC, utilizando la pasada del día 3 a las 00 UTC, se puede observar en las Figuras 59.3 y 59.4 en la página siguiente cómo el valor medio refleja la existencia de una circulación cerrada, si bien existe mucha incertidumbre en torno a la posición de la DANA, con dos máximos de la desviación estándar normalizada situados respectivamente al noreste y al suroeste de la DANA. Este patrón está asociado con una alta incertidumbre, no solo en la intensidad de la perturbación (profundidad de la DANA), sino también en su posición y su evolución temporal. Un importante número de miembros del ensemble parece retrasado y/o más hacia el suroeste, mientras que otra fracción importante parece adelantada y/o hacia el noreste. En realidad, las discrepancias temporales y espaciales irán ligadas, ya que cuanto más al sur se sitúe la DANA, menor será su interacción con la fuerte circulación meridional y, por tanto, menor su velocidad de desplazamiento hacia el este.

Para el día 7 a las 00 UTC, la incertidumbre es aún mayor y el valor medio no refleja la existencia de una circulación cerrada. Además, la desviación estándar, más allá de constatar la alta dispersión, nos da poca información respecto a la distribución de los miembros del ensemble y los posibles escenarios con los que podríamos encontrarnos. 

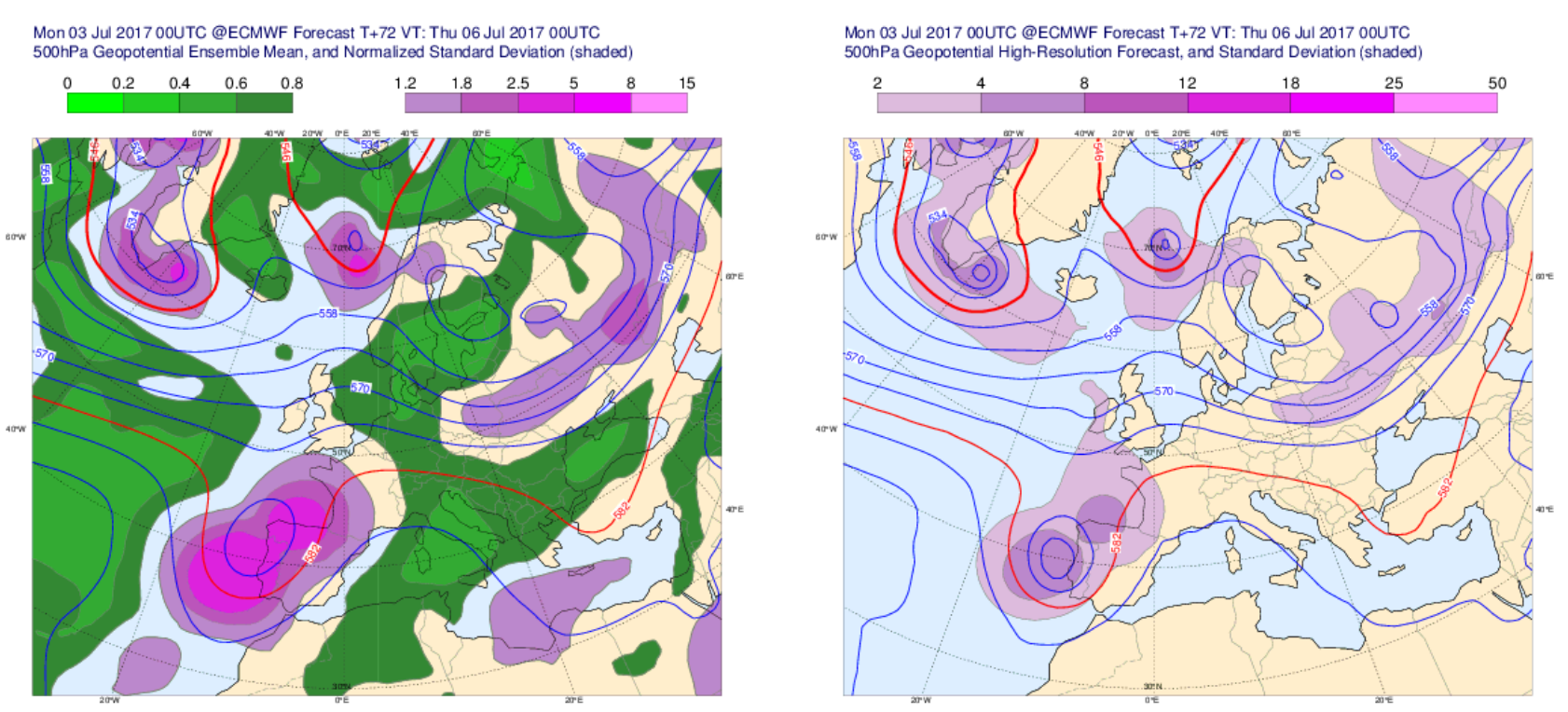

Figura 59.3: Izquierda: altura geopotencial en $500 \mathrm{hPa}$ del valor medio del ECENS y su desviación estándar normalizada para las 00 UTC del 06-07-2017, a partir de la pasada de 00 UTC del 03-07-2017 del ECENS. Derecha: altura geopotencial en $500 \mathrm{hPa}$ del ECHRES y desviación estándar del ECENS, para las 00 UTC del 06-07-2017, a partir de la misma pasada de 00 UTC del 03-07-2017 de ambos sistemas. ECMWF.
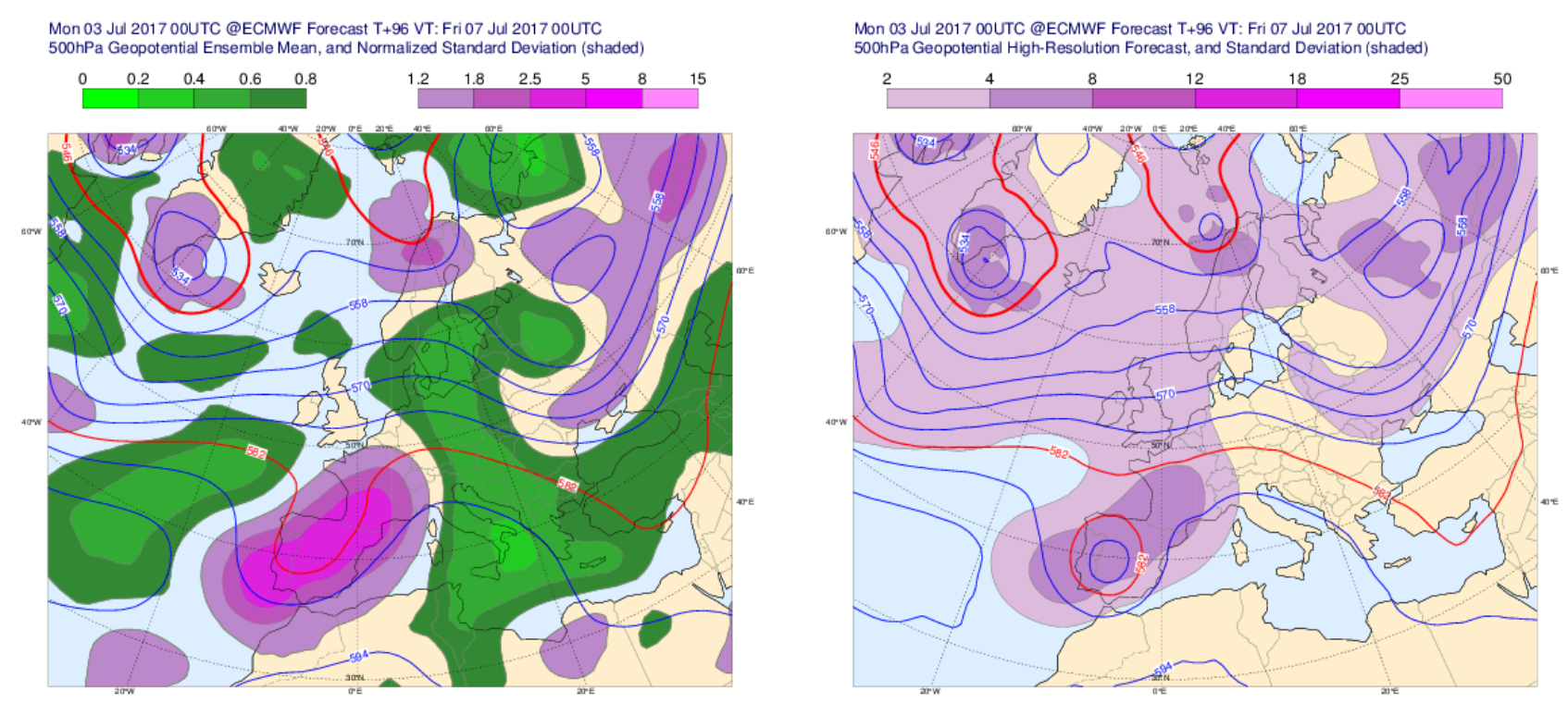

Figura 59.4: Como en la Figura 59.3, pero para el día 07-07-2017. ECMWF.

Para analizar más en detalle el comportamiento del ECENS y asegurarnos de tener en cuenta los 51 miembros del ensemble, es conveniente recurrir a otros tipos de representación. La técnica de clusters o agrupaciones en grupos y supergrupos nos permite visualizar los distintos escenarios que podrían darse y el número de miembros que los apoyan (secs. 27.4.1 en la página 406 y 27.4.2 en la página 409). En la Figura 59.5 en la página siguiente se puede observar su representación para el día 6 a las 12 UTC, para la pasada del día 3 a las 00 UTC.
Los seis grupos representan distintas situaciones que se distinguen por el mayor o menor «descuelgue» de la DANA. Si vemos los supergrupos, tendríamos fundamentalmente tres escenarios: un primer escenario (A) en el que la DANA se sitúa sobre el noroeste peninsular, escenario que engloba a más de la mitad de los miembros y al control; un segundo escenario (B) en el que la DANA se sitúa sobre el cantábrico y continúa bastante ligada al flujo zonal y, finalmente, un tercer escenario $(\mathrm{C})$ que sinópticamente se parece al primero, aunque la DANA es más profunda y se sitúa más hacia el suroeste. 


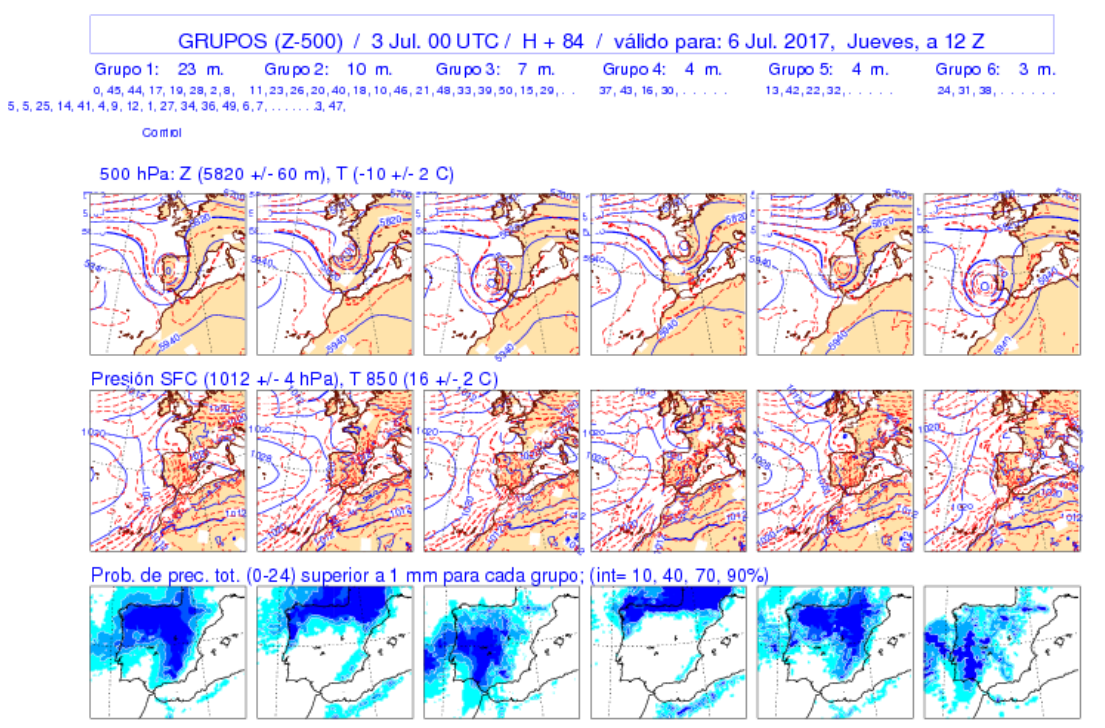

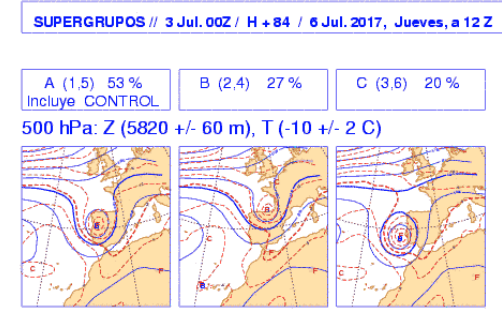
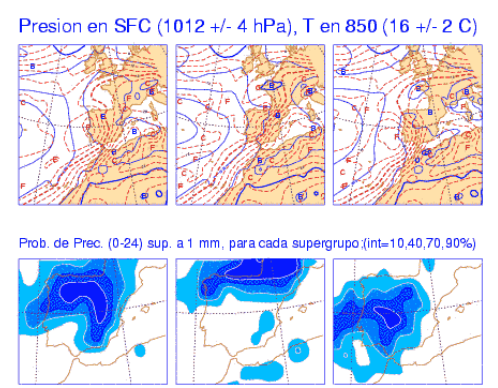

Figura 59.5: Paneles de la izquierda: Grupos del ECENS para las 12 UTC del 06-07-2017, a partir de la pasada de 00 UTC del 03-07-2017 del ECENS. Paneles de la derecha: Supergrupos escogidos a partir de los grupos. Fuente: AEMET.

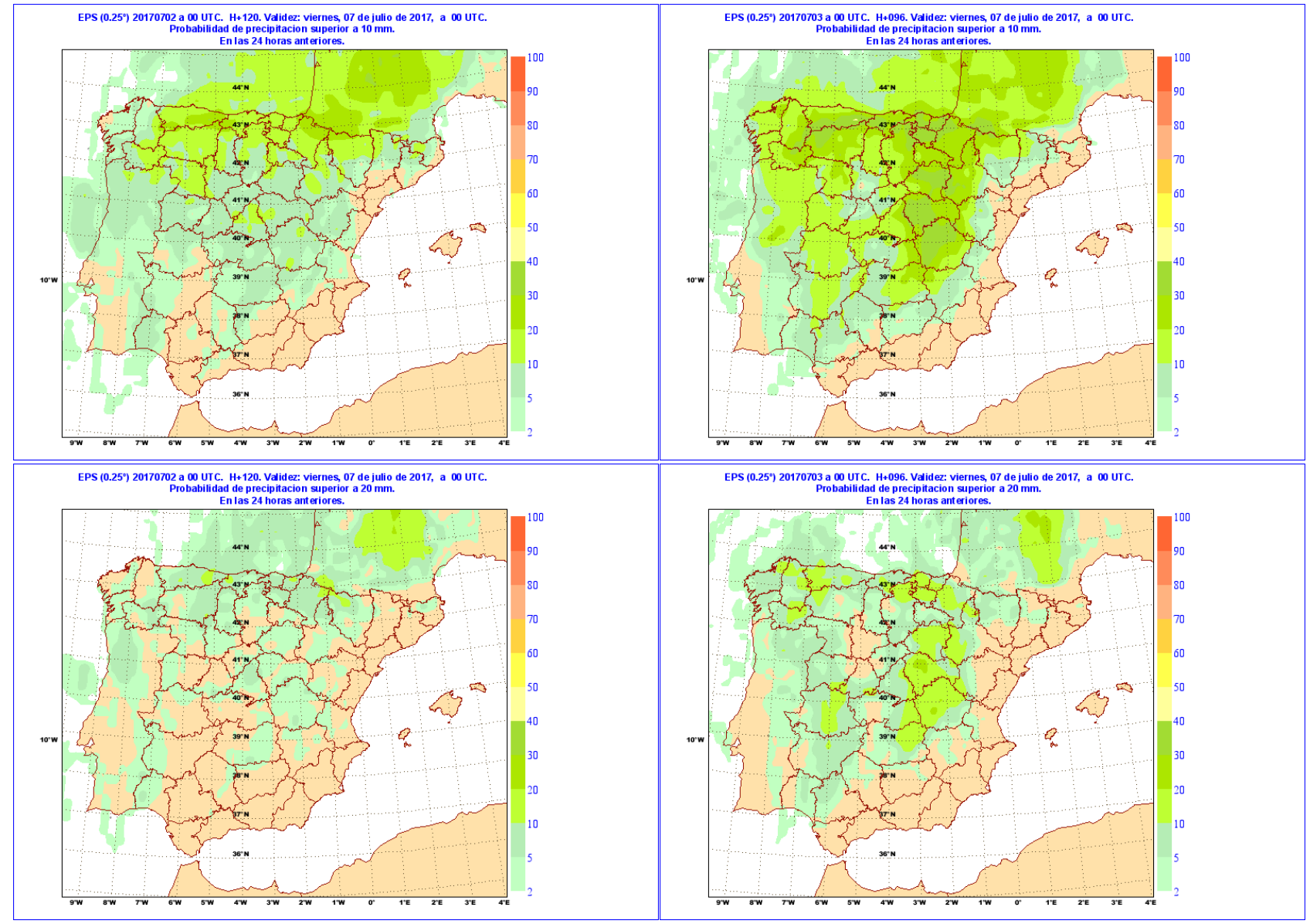

Figura 59.6: Mapas de probabilidad de superación de los umbrales de precipitación de $10 \mathrm{~mm}$ (arriba) y $20 \mathrm{~mm}$ (abajo) en 24 horas, previstos para el 06-07-2017, a partir de las pasadas de 00 UTC del 02-07-2017 (izquierda) y de 00 UTC del 03-07-2017 (derecha) del ECENS. Fuente: AEMET. 
Debido a la presencia de una depresión aislada en niveles altos hay una considerable incertidumbre a pesar de la proximidad del día. Es probable que en el entorno de Galicia, Cantábrico, alto Ebro y Pirineos, esté nuboso con precipitaciones y tormentas, que podrán ser localmente fuertes en zonas de montaña. En gran parte del resto del interior y del sur peninsular no puede descartarse que también esté nuboso con precipitaciones y tormentas, que podrían ser localmente fuertes en zonas de montaña, de forma algo más probable en el centro este y algo menos probable en el centro oeste. En el litoral mediterráneo oriental peninsular y en Baleares son probables los intervalos de nubes medias y altas, así como intervalos de nubosidad de evolución. En las islas occidentales de Canarias estará nuboso con lluvias débiles en el norte, y poco nuboso en el sur. Intervalos nubosos en las orientales.

Figura 59.7: Predicción general de medio plazo emitida por AEMET el día 3 de julio para el día del episodio, jueves 6 de julio (un D+3).

Volviendo atrás, si consideramos las pasadas del ECHRES del día 2 a las 12 UTC y del día 3 a las 00 UTC, podríamos considerarlas dentro de los supergrupos B y A respectivamente. Si observamos el patrón de precipitaciones de ambos supergrupos, podemos constatar que sitúan las precipitaciones en áreas prácticamente disjuntas, lo que hace muy difícil precisar, en el medio plazo, las zonas donde van a producirse las precipitaciones más intensas. Esto se puede ver claramente en la Figura 59.6 en la página anterior, donde se representan los mapas de probabilidad de precipitación en 24 horas superiores a determinados umbrales, en este caso $10 \mathrm{~mm}$ y $20 \mathrm{~mm}$, observándose zonas muy extensas con probabilidades superiores al $20 \%$ (10\% para $20 \mathrm{~mm}$ ), pero nunca superiores al $40 \%$ (30\% para $20 \mathrm{~mm})$.

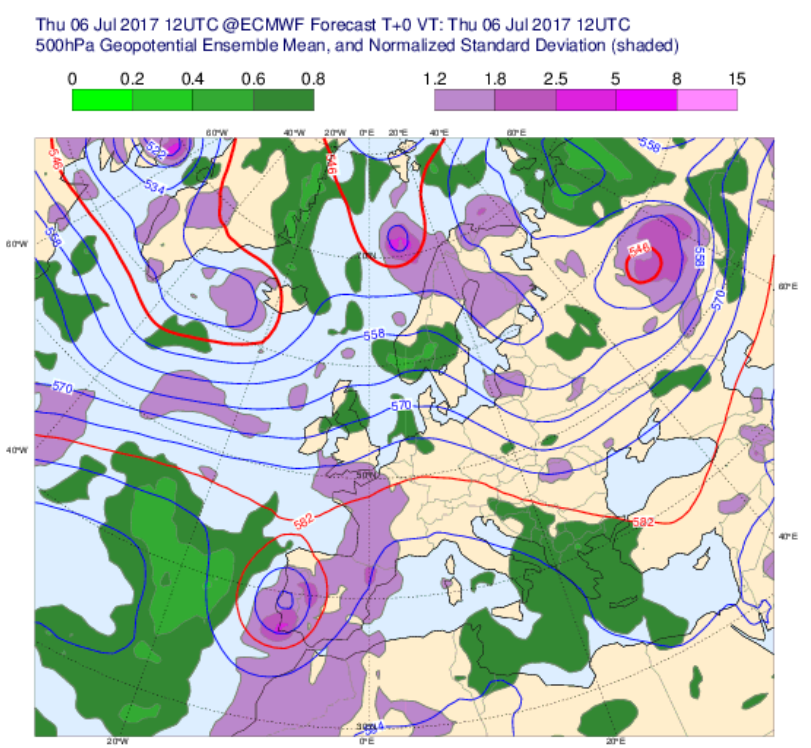

\subsection{Propuesta de predicción}

Según todo lo visto anteriormente, tratar de hacer una predicción el día 3 de julio para el jueves 6 de julio (un D+3) utilizando únicamente las probabilidades parece insuficiente. Por ello, además de utilizar los términos probabilistas habituales en la predicción de medio plazo, es conveniente hacer mención de los distintos escenarios y sus probabilidades. La predicción general de medio plazo realizada por AEMET para ese día puede verse en la Figura 59.7.

Como vemos, esta predicción recoge la impredecibilidad de la situación, pero debido a la rigidez de dicho producto (texto limitado en tamaño y terminología), no permite transmitir al usuario toda la cantidad de información y riqueza conceptual que el predictor, con su experiencia y saber hacer, saca de los modelos.

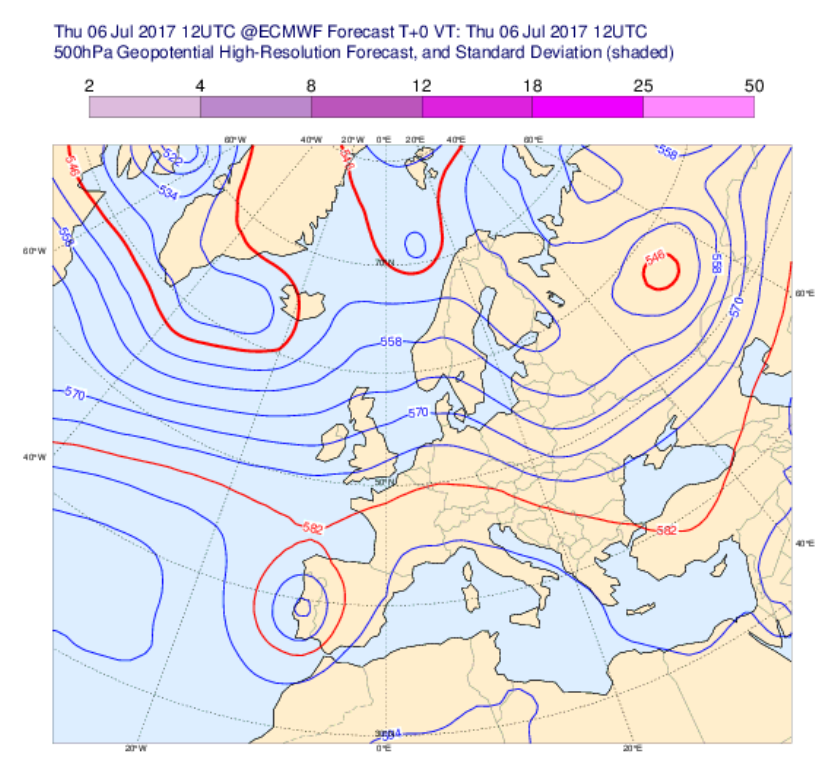

Figura 59.8: Izquierda: análisis del geopotencial en 500 hPa del valor medio del ECENS y su desviación estándar normalizada entre las 12 UTC del 06-07-2017 y del 07-07-2017, a partir de la pasada 2017070612. Derecha: Análisis del geopotencial en 500 hPa del ECHRES y desviación estándar del ECENS, entre las 12 UTC del 06-07-2017 y del 07-07-2017, a partir de la misma pasada. ECMWF. 

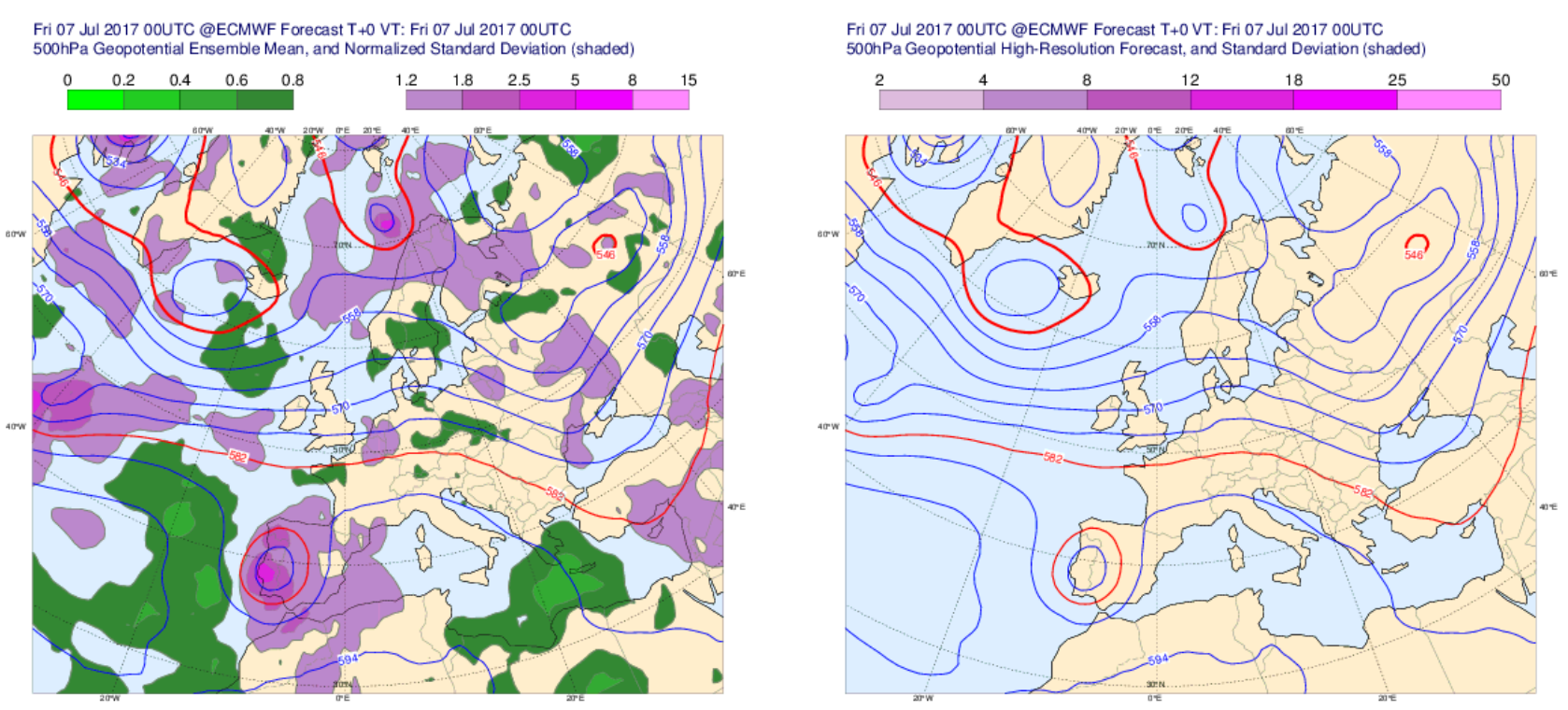

Figura 59.9: Como en la Figura 59.8 en la página anterior, ahora con la pasada 2017070700 ECMWF.
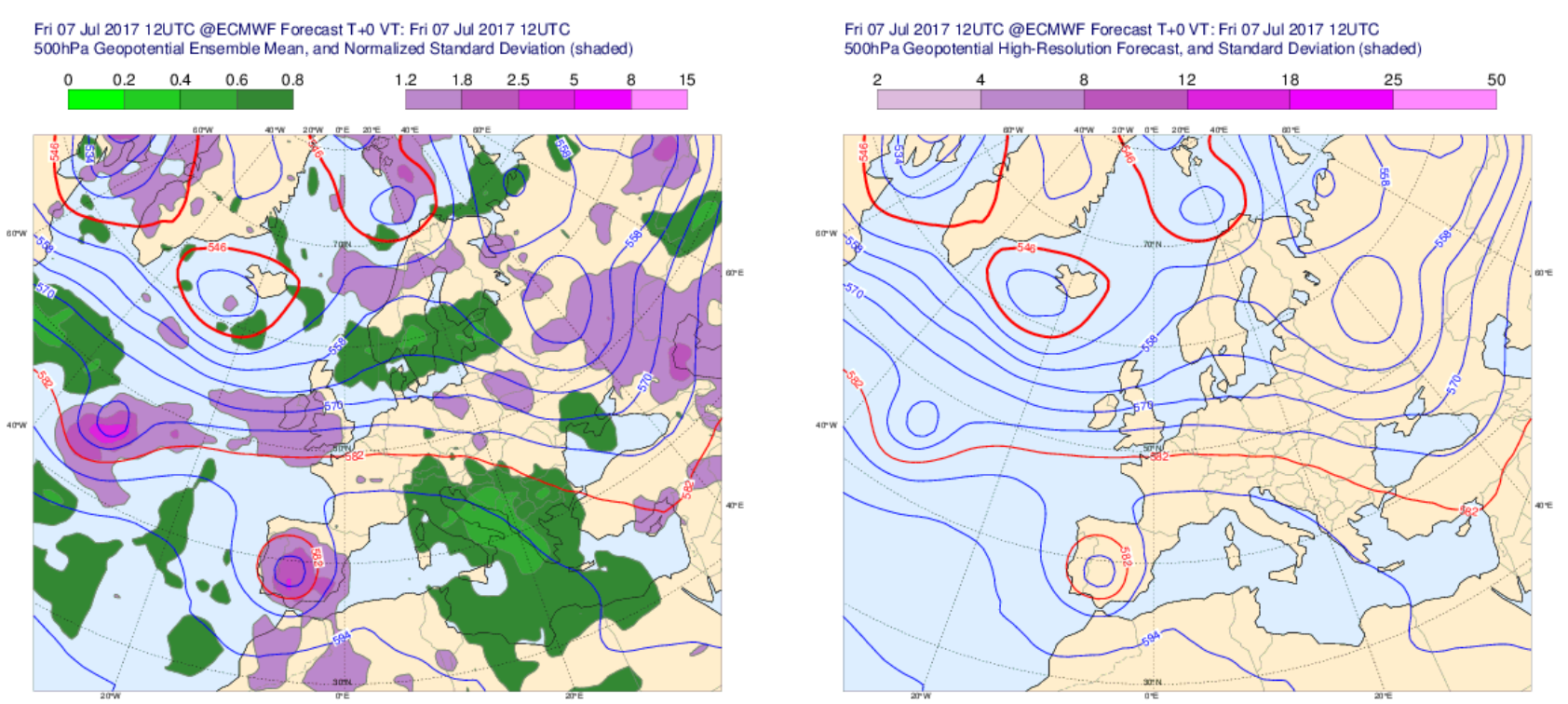

Figura 59.10: Como en la Figura 59.8 en la página anterior, ahora con la pasada 2017070712. ECMWF.

\subsection{Análisis de la situación}

Análisis objetivo usando ECHRES y ECENS. Para la situación podemos considerar el análisis objetivo del ECHRES, en las Figuras 59.8 en la página anterior, 59.9 y 59.10. A las 12 UTC del jueves 6 de julio la DANA se situó sobre el oeste peninsular, centrada sobre el río Tajo y en las siguientes 24 horas se desplazó zonalmente hacia el centro peninsular mientras se rellenaba ligeramente. Volviendo a los supergrupos del jueves 6 de julio a las 12 UTC, podemos decir que la situación real fue recogida entre los supergrupos $\mathrm{A}$ y $\mathrm{C}$, algo más al sur que en el supergrupo A y algo más al este que en el C.
Análisis subjetivo y satélite. En los análisis de superficie de la Figura 59.11 en la página siguiente, sobre la imagen de satélite se superponen símbolos asociados a discontinuidades dinámicas y térmicas o ligados a la estabilidad en la troposfera media-baja. La DANA vino acompañada de chubascos tormentosos orientados de $\mathrm{N}$ a S dentro de la banda baroclina, representada como una banda cálida organizada. Por delante, se dieron otras líneas de inestabilidad con convección de base elevada y posibles reventones cálidos en zonas del SE peninsular. Además, se produjeron algunas tormentas con granizo dentro del núcleo frío de la DANA. La convección, que no cesó por las noches, sí tuvo un aumento de la actividad asociado al ciclo diurno. 

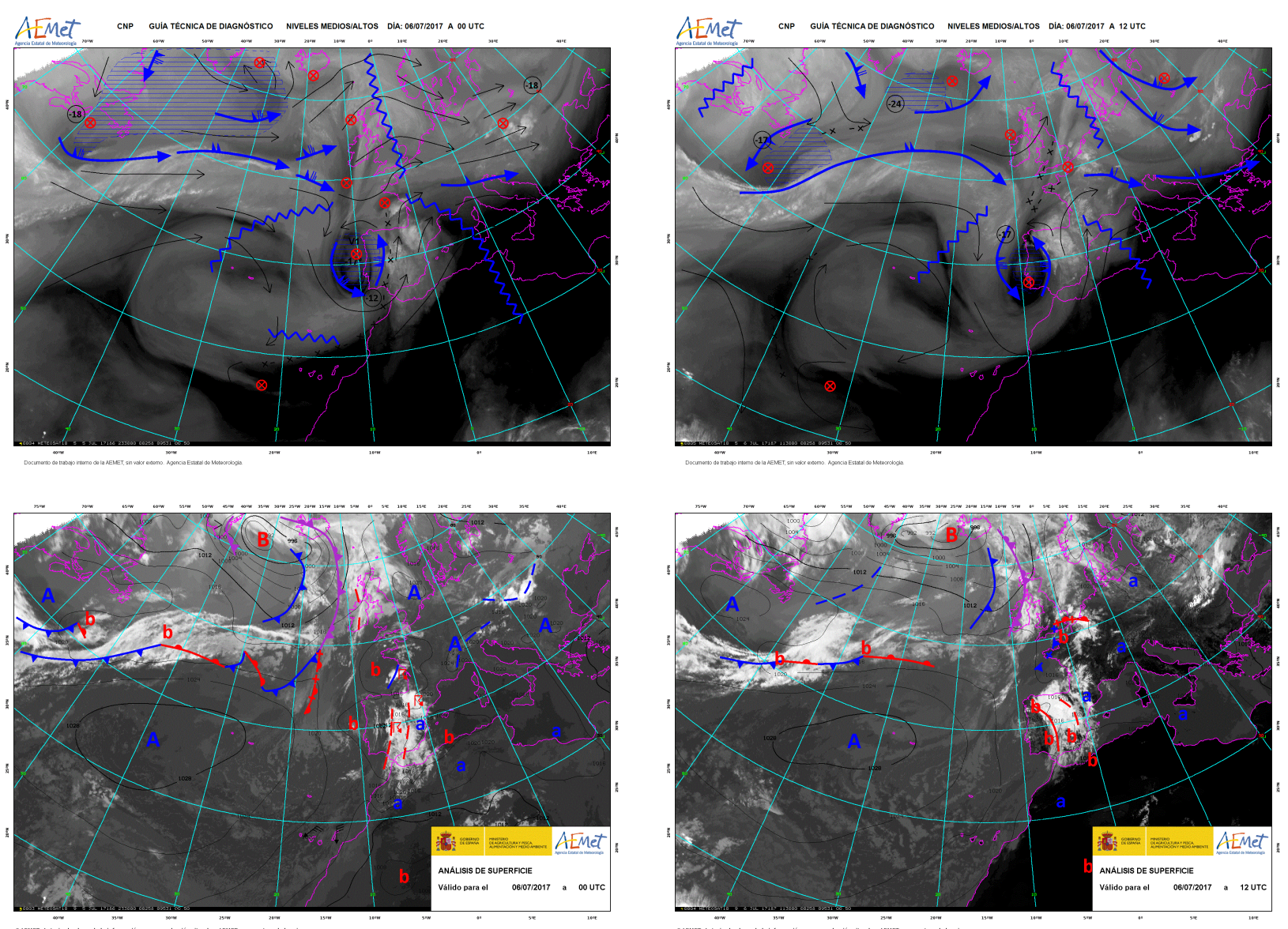

Figura 59.11: Diagnosis de niveles medios-altos (arriba) y niveles bajos (abajo) para las 00 UTC y 12 UTC del 06-07-2017. AEMET

Las mayores acumulaciones de precipitación se produjeron en el entorno del sistema Central, entre las provincias de Ávila y Madrid, con numerosas estaciones por encima de los $80 \mathrm{~mm} / 24$ horas, destacando los 102 mm/24 horas de la estación de Rozas de Puerto Real o los 80 mm/24 horas del observatorio de Ávila.
También destacan los $98 \mathrm{~mm} / 24$ horas registrados en Cuenca. Por otro lado, es llamativo el solape que se produce entre precipitaciones y rayos (Figuras 59.12 y 59.13 en la página siguiente), señal inequívoca del carácter tormentoso de todas las precipitaciones que se produjeron.
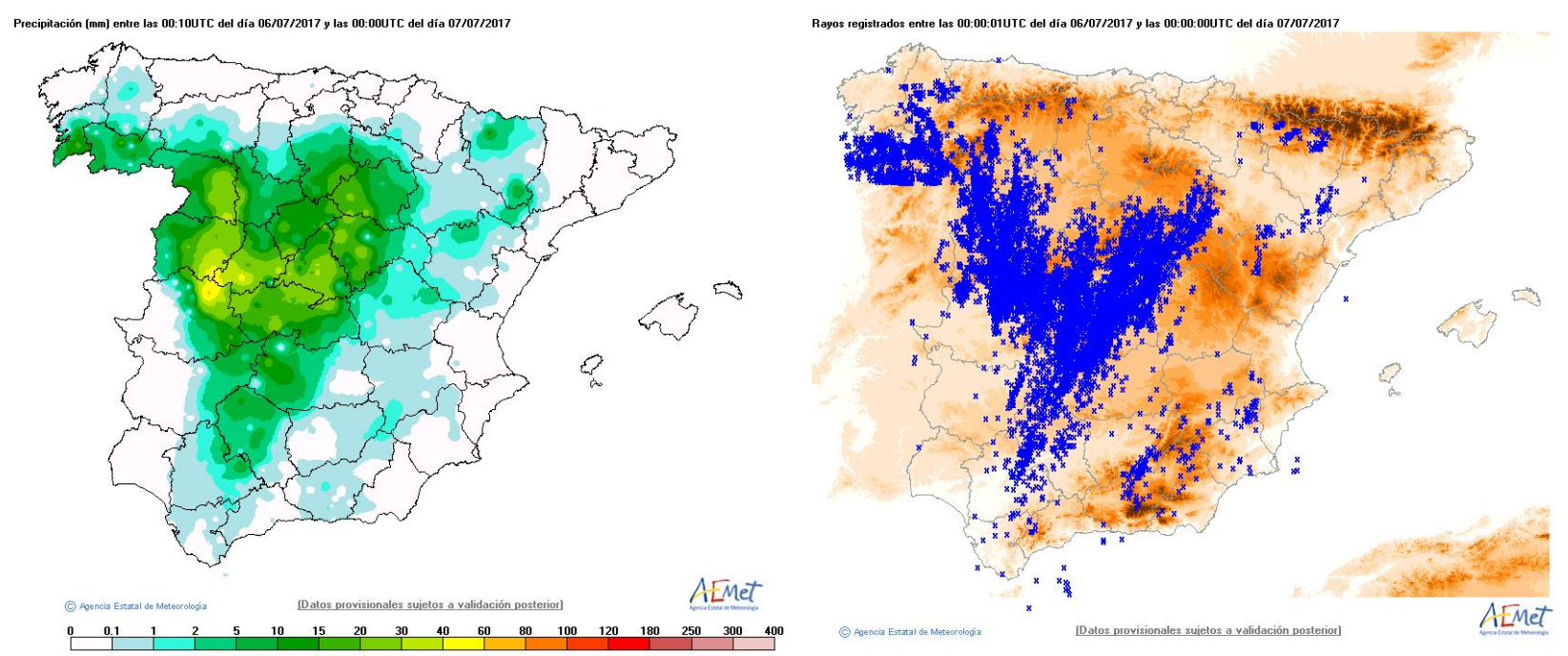

Figura 59.12: Precipitaciones acumuladas y rayos observados del día 06-07-2017. 


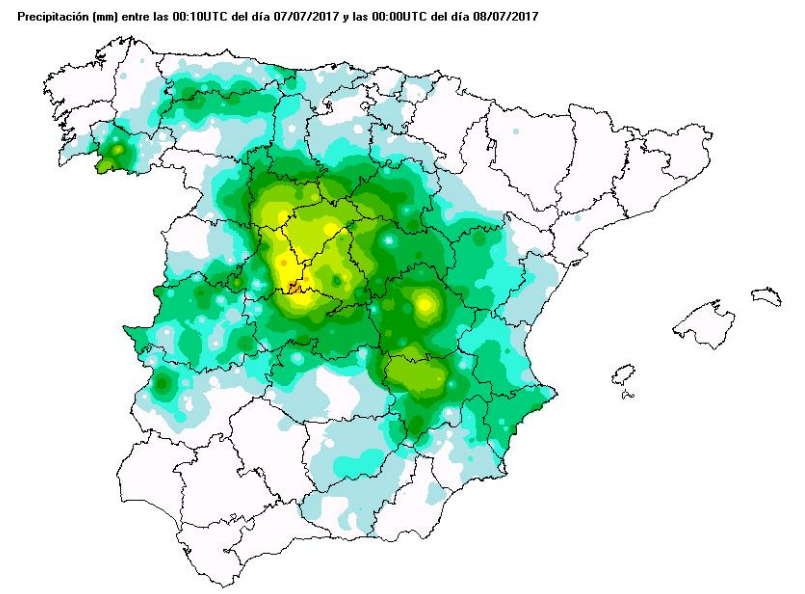

AEMet

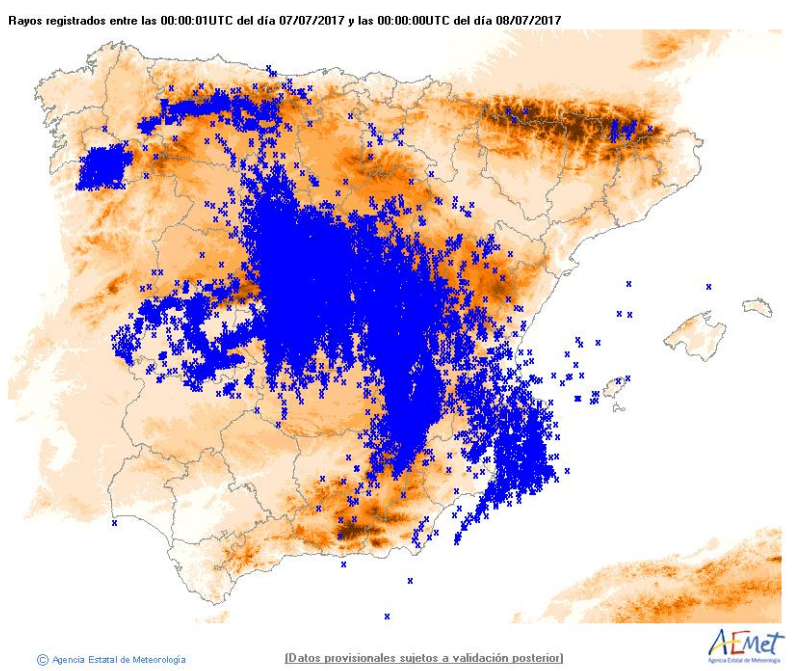

Figura 59.13: Precipitaciones acumuladas y rayos observados del día 07-07-2017.

En cuanto al viento (Figuras 59.14, 59.15 en la página siguiente y 59.16 en la página siguiente), los intervalos fuertes y muy fuertes asociados a la convección fueron generalizados, destacando el registro del aeropuerto de Barajas, donde se llegaron alcanzar los $146 \mathrm{~km} / \mathrm{h}$ durante una tormenta.

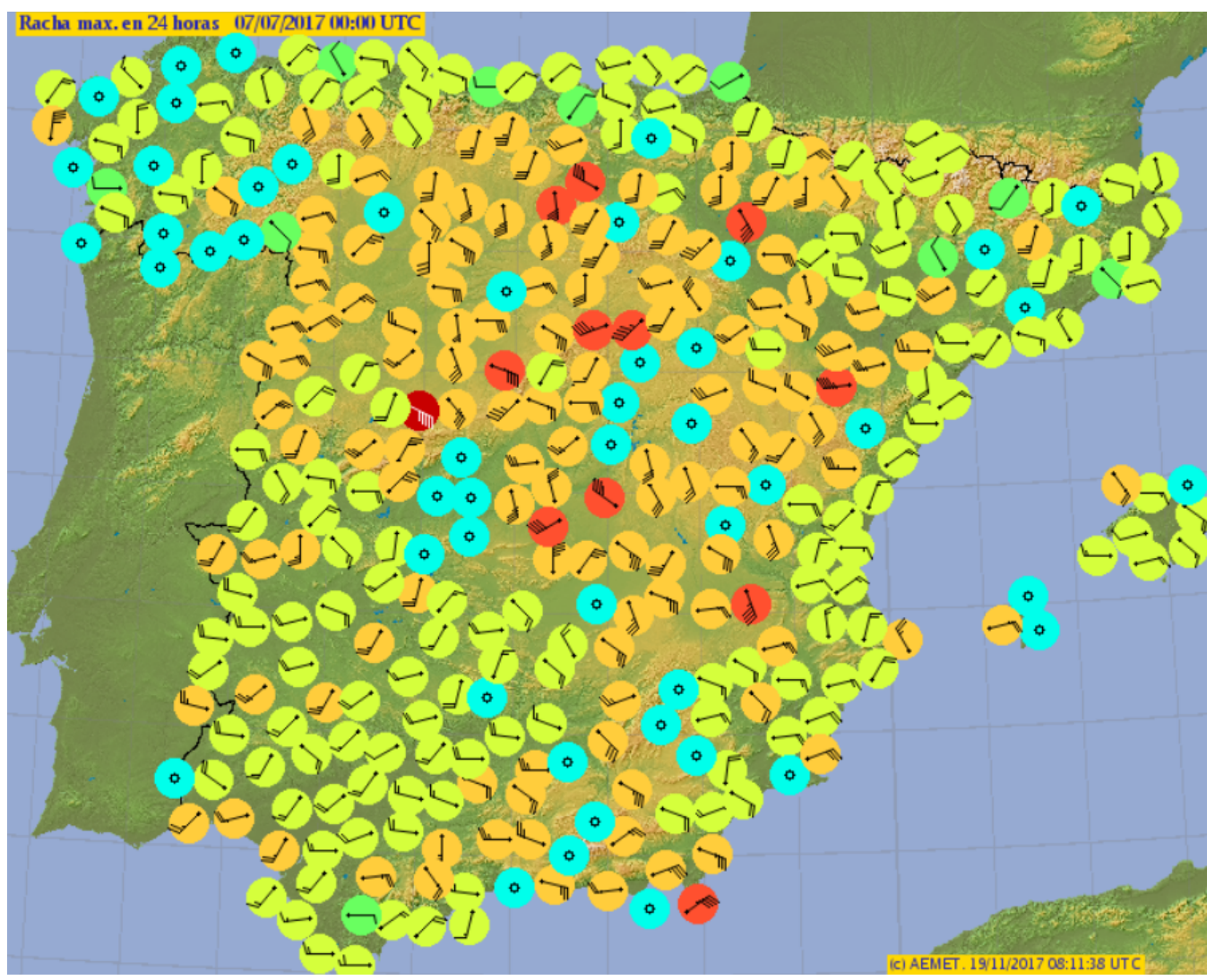

Figura 59.14: Rachas máximas observadas el día 06-07-2017. 


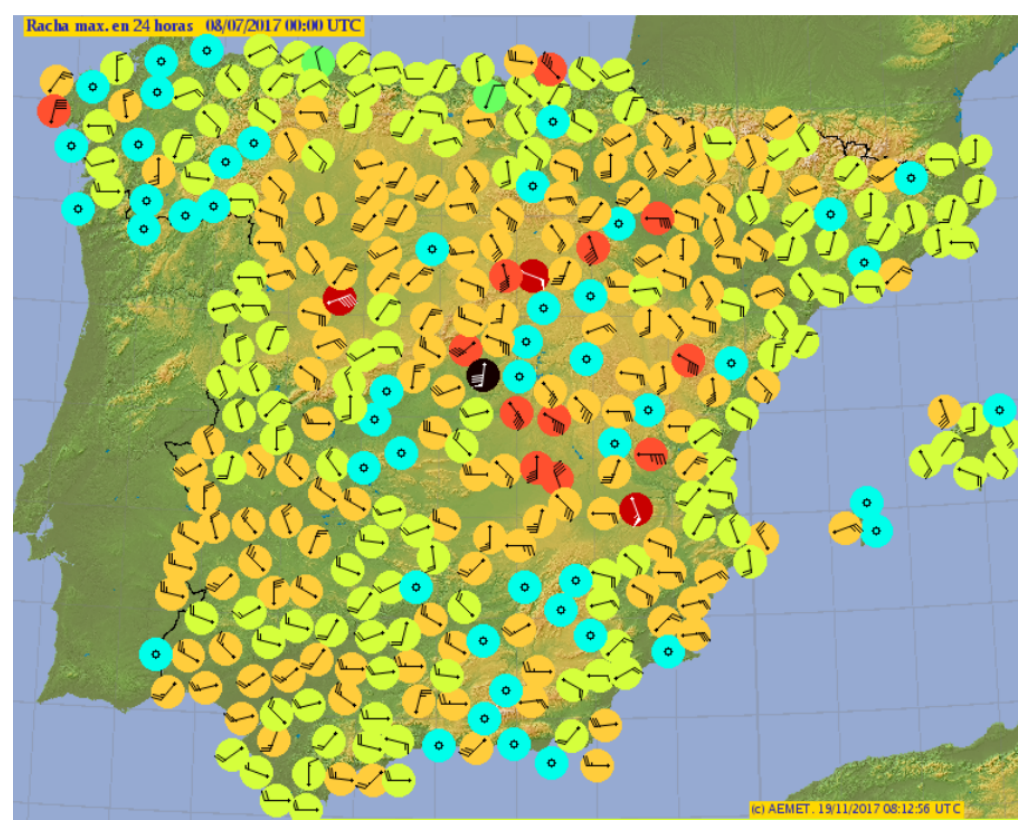

Figura 59.15: Rachas máximas observadas el día 07-07-2017.
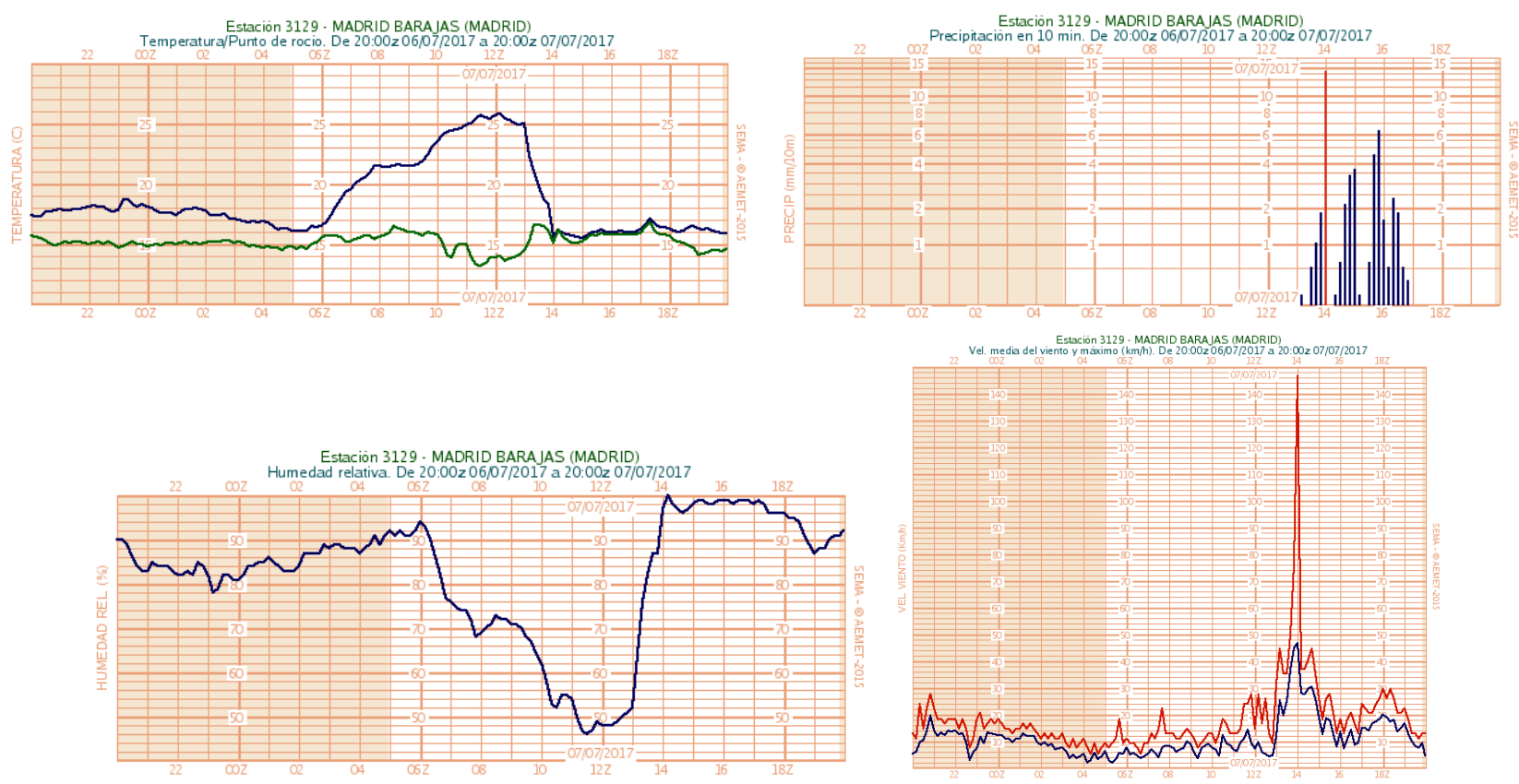

Figura 59.16: Temperatura/punto de rocío, precipitaciones diez-minutales, humedad relativa y velocidad media del viento y máximo para el periodo entre las 20 UTC del 06-07-2017 y las 20 UTC del 07-07-2017, registradas en el Aeropuerto de Madrid/Barajas.

En las figuras se puede apreciar que el máximo de la racha coincide con un chubasco de $15 \mathrm{~mm} / 10 \mathrm{~min}$, dentro de un periodo en el que se produjo un brusco descenso de la temperatura, de $10^{\circ} \mathrm{C} / 1$ hora. En la Figura 59.17 en la página siguiente (izquierda) se puede observar un fotograma de un video de un aficionado que captó el chubasco.
Si analizamos los impactos adversos asociados al paso de la DANA, los más importantes fueron la rotura de una pesa en el municipio cacereño de Valverde de la Vera [5], y los que produjeron en Madrid y su área metropolitana, donde los bomberos de la Comunidad de Madrid llegaron a realizar 140 intervenciones, sobre todo por retirada de ramas, saneamientos de fachadas $\mathrm{y}$ achiques de agua $[1,3]$. 

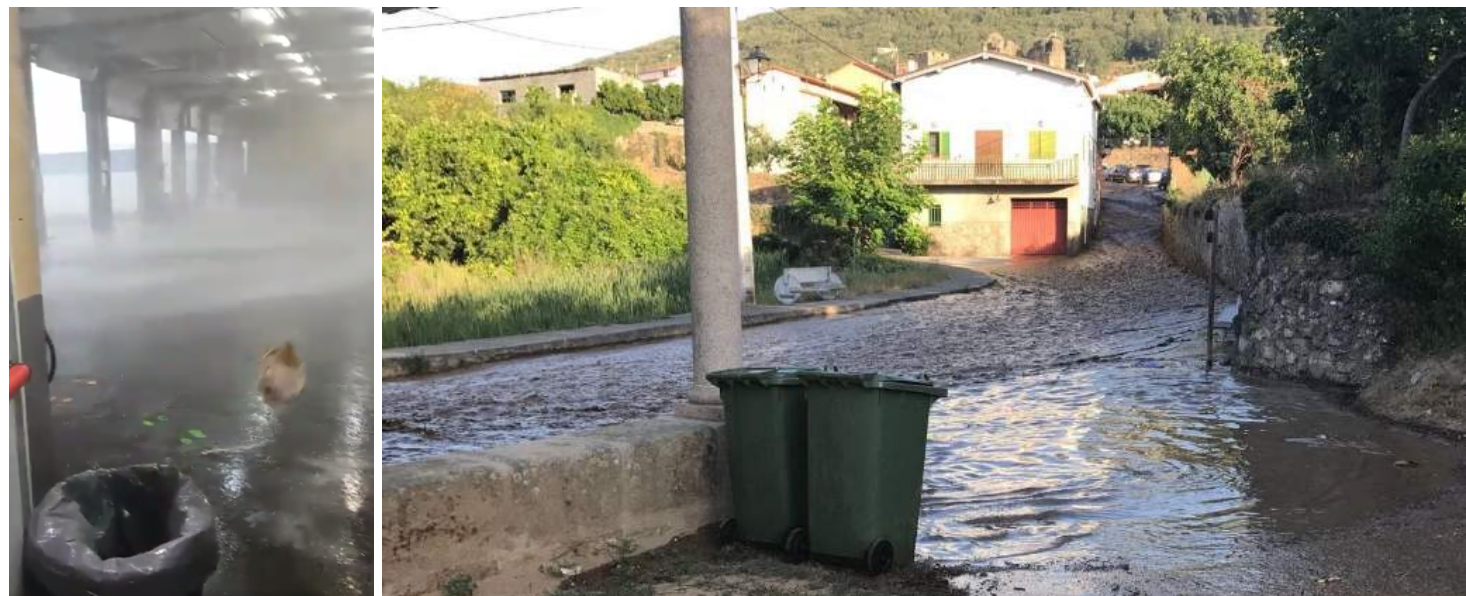

Figura 59.17: Izquierda: Fotograma de un video realizado en el Aeropuerto de Madrid/Barajas donde se aprecia la entrada de agua en unos hangares debido al fuerte viento el 07-07-2017. Derecha: Inundaciones producidas en Valverde de la Vera el 07-07-2017. Junta de Extremadura [3, 4].
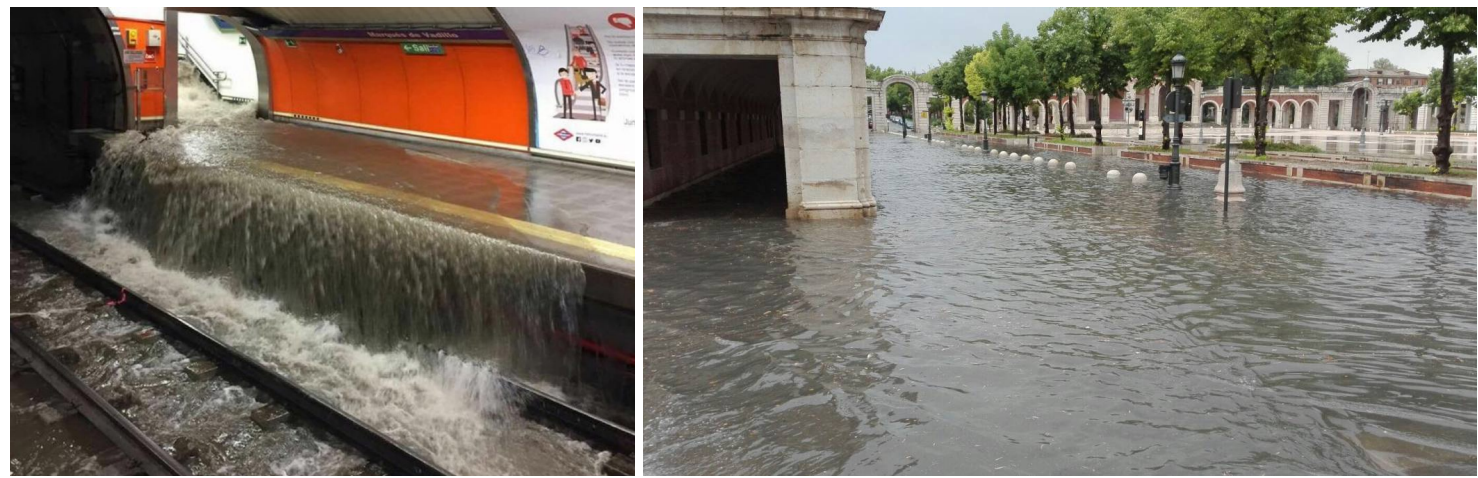

Figura 59.18: Izquierda: Inundaciones producidas en la Estación de Metro de Marqués de Vadillo el 07-072017 (https: //www. facebook. com/ oscar. ruiz. 5074644/posts/10211980967152530). Derecha: Inundaciones producidas en Aranjuez el 07-07-2017. El País [1].

\subsection{Conclusiones}

Los episodios de lluvias intensas provocadas por depresiones aisladas en niveles altos presentan, a menudo, mucha incertidumbre y por ende poca predecibilidad. En este episodio el examen de los tres escenarios marcados por el sistema ECENS que marcaban zonas de precipitación prácticamente excluyentes, así como los mapas de probabilidad correspondientes, muestran una elevadísima incertidumbre. La predicción emitida por AEMET en formato texto tres días antes del evento (medio plazo) denota así mismo esa elevada incertidumbre, dando alta probabilidad de lluvias intensas y tormentas en el norte peninsular, pero sin descartar que se dieran en otras zonas del interior del centro peninsular. Las precipitaciones más intensas y rayos registrados no se dieron en el norte, la zona indicada como la más probable, sino en el centro, donde ya se avisaba que podrían también darse. Por tanto, en situaciones tan poco predecibles, donde existe enorme incertidumbre tanto en el medio como en el corto plazo, el uso de SPC es fundamental, aun teniendo en cuenta que su resolución horizontal no alcanza a resolver todos los fenómenos convectivos que puedan tener lugar y, por ello, se puedan subestimar precipitaciones o rachas de viento que puedan llegar a producirse. A medida que el episodio se acerca, es de gran ayuda contrastar la predicción con las siguientes pasadas de los modelos y, entrando en el corto plazo, apoyar con la información aportada por los modelos de alta resolución disponibles (e. g. HARMONIE-AROME, sec. 20.4 en la página 310 ), para poder precisar las zonas que se verán afectadas. 


\subsection{Referencias}

[1] BARRoso, F. J. La lluvia obliga a cortar la M-40 y la A-42 por balsas de agua. Madrid, jul. de 2017. URL: https: //elpais . com / ccaa / 2017 / 07 / 06 / madrid / 1499361476_173135. html (citado en páginas 888,889$)$.

[2] Cuevas Agulló, Emilio y Rodríguez, José. "Estadística de depresiones aisladas en niveles altos". En: $5^{\circ}$ Simposio Nacional de Predicción. Madrid: Instituto Nacional de Meteorología, 2001. URL: http : / / hdl . handle. net/20 .500.11765/4710 (citado en página 880 ).

[3] Domínguez, Gustavo. Aeropuerto de Madrid Adolfo Suarez barajas.. T 4...Ayer. 2017.
URL: https : / / twitter . com / Gus _ texeda / status / $88368191393599897 \overline{9}$ (visitado 20-11-2017) (citado en páginas 888,889$)$.

[4] EFE - ABC. Una fisura en una balsa, origen de las inundaciones en Valverde de la Vera. Mérida, jul. de 2017. URL: https : / /www . abc.es/sociedad/abci-rompe-presavalverde - vera - aunque - no - danos personales - 201707051029 _ noticia . html (citado en página 889).

[5] EFE - El PAís. La presa de Valverde de la Vera revienta y provoca inundaciones. Mérida, jul. de 2017. URL: https://politica. elpais . com / politica / 2017 / 07 / 05 / actualidad/1499245364_112565.html (citado en página 888 ). 
